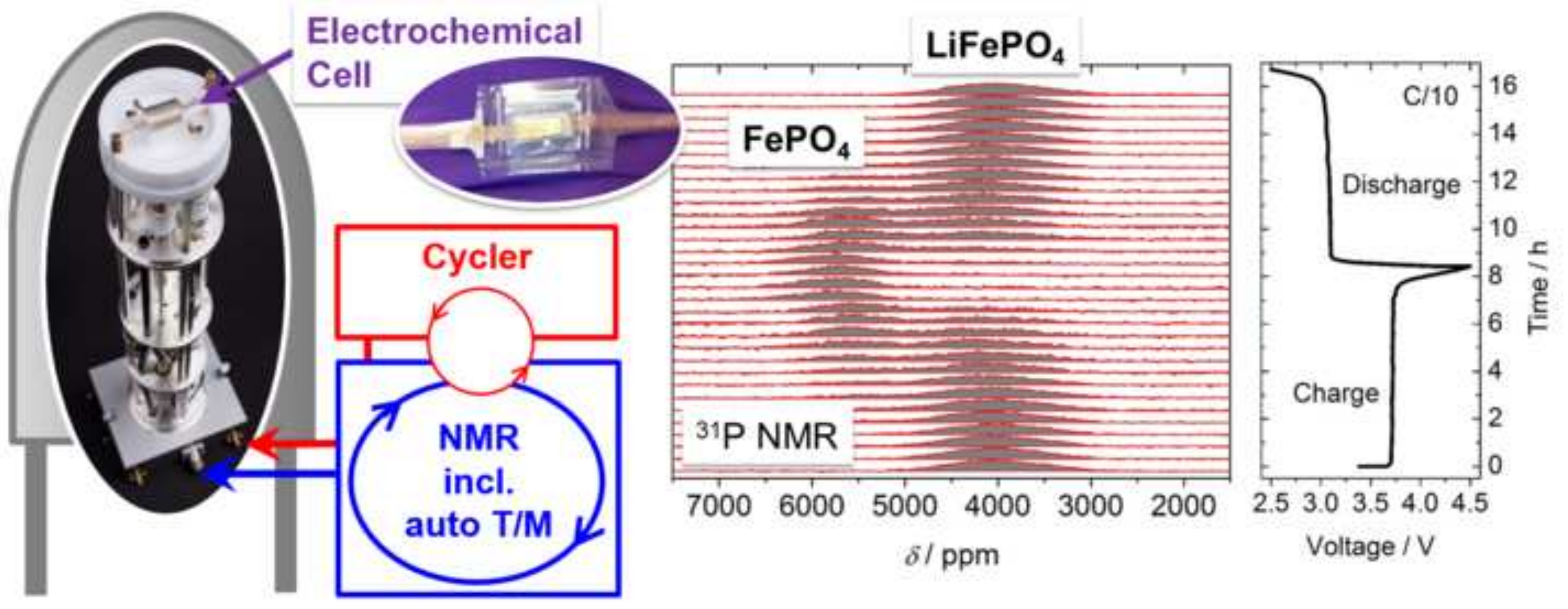




\title{
Automatic Tuning Matching Cycler (ATMC) In Situ NMR Spectroscopy as a Novel Approach for Real-Time Investigations of Li- and Na-lon Batteries
}

\author{
Oliver Pecher ${ }^{1}$, Paul M. Bayley ${ }^{1}$, Hao Liu ${ }^{1}$, Zigeng Liu ${ }^{1}$, Nicole M. Trease ${ }^{1}$, and Clare P. Grey ${ }^{1, *}$ \\ ${ }^{1}$ University of Cambridge, Department of Chemistry, Lensfield Road, Cambridge CB2 1EW, UK \\ * Corresponding author: Prof. Clare P. Grey, Email: cpg27@cam.ac.uk, Fax: +44 1223336300
}

Keywords: In situ NMR, Li-ion battery, Na-ion battery, Paramagnetism

\begin{abstract}
We have developed and explored the use of a new Automatic Tuning Matching Cycler (ATMC) in situ NMR probe system to track the formation of intermediate phases and investigate electrolyte decomposition during electrochemical cycling of Li- and Na-ion batteries (LIBS and NIBS). The new approach addresses many of the issues arising during in situ NMR, e.g., significantly different shifts of the multi-component samples, changing sample conditions (such as the magnetic susceptibility and conductivity) during cycling, signal broadening due to paramagnetism as well as interferences between the NMR and external cycler circuit that might impair the experiments. We provide practical insight into how to conduct ATMC in situ NMR experiments and discuss applications of the methodology to $\mathrm{LiFePO}_{4}$ (LFP) and $\mathrm{Na}_{3} \mathrm{~V}_{2}\left(\mathrm{PO}_{4}\right)_{2} \mathrm{~F}_{3}$ cathodes as well as $\mathrm{Na}$ metal anodes. Automatic frequency sweep ${ }^{7} \mathrm{Li}$ in situ NMR reveals significant changes of the strongly paramagnetic broadened LFP line shape in agreement with the structural changes due to delithiation. Additionally, ${ }^{31} \mathrm{P}$ in situ NMR shows a full separation of the electrolyte and cathode NMR signals and is a key feature for a deeper understanding of the processes occurring during charge/discharge on the local atomic scale of NMR. ${ }^{31} \mathrm{P}$ in situ NMR with "on-the-fly" re-calibrated, varying carrier frequencies on $\mathrm{Na}_{3} \mathrm{~V}_{2}\left(\mathrm{PO}_{4}\right)_{2} \mathrm{~F}_{3}$ as a cathode in a NIB enabled the detection of different $P$ signals within a huge frequency range of $4000 \mathrm{ppm}$. The experiments show a significant shift and changes in the number as well as intensities of ${ }^{31} \mathrm{P}$ signals during desodiation/sodiation of the cathode. The in situ experiments reveal changes of local $\mathrm{P}$ environments that in part have not been seen in ex situ NMR investigations. Furthermore, we applied ATMC ${ }^{23} \mathrm{Na}$ in situ NMR on symmetrical $\mathrm{Na}-\mathrm{Na}$ cells during galvanostatic plating. An automatic adjustment of the NMR carrier frequency during the in situ experiment ensured onresonance conditions for the $\mathrm{Na}$ metal and electrolyte peak, respectively. Thus, interleaved measurements with different optimal NMR set-ups for the metal and electrolyte, respectively, became possible. This allowed the formation of different Na metal species as well as a quantification of electrolyte consumption during the electrochemical experiment to be monitored. The new approach is likely to benefit a further understanding of Na-ion battery chemistries.
\end{abstract}

\section{Graphical Abstract}

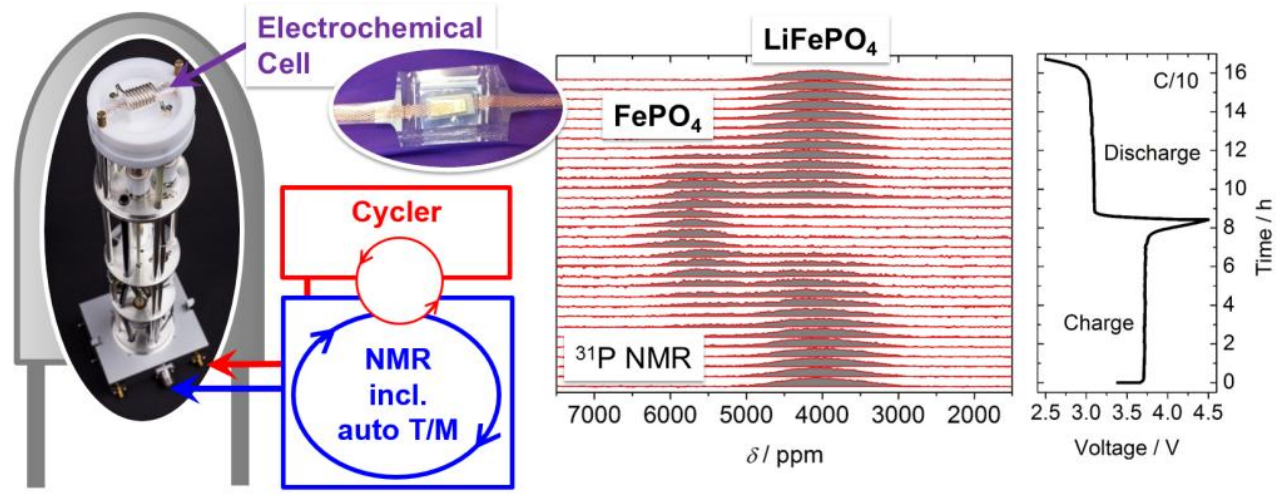




\section{Introduction}

The expected increase in global energy consumption along with the demand for reduced or zeroemissions energy sources have raised the awareness of the need for efficiency and sustainability. Electricity production from our natural renewable resources requires the development of efficient electrical storage systems to balance demand with supply. In addition, more reliable and improved/cheaper storage systems are needed to move from the more common internal combustion engines and hybrid electrical vehicles to all-electric vehicles [1]. Li-ion batteries (LIBs) $[2,3]$ represent promising storage systems, offering several appealing attributes: $L i$ is the lightest metallic element and its very low redox potential of $E^{0}\left(\mathrm{Li}^{\mathrm{i}} \mathrm{Li}^{+}\right)=-3.04 \mathrm{~V}$ vs. the standard hydrogen electrode (SHE) results in cells with high voltage and energy density. Furthermore, the small $\mathrm{Li}^{+}$radius is beneficial for diffusion in solids. Coupled with its long cycle life and good capacity retention, these properties have enabled LIBs to capture the portable electronics market $[4,5]$. While this technology is quite mature, there remain questions regarding Li battery safety, energy density, lifetime, low-temperature performance and cost. Furthermore, as the use of large-scale LIBs becomes widespread, increasing demand for Li commodity chemicals combined with geographicallyconstrained $\mathrm{Li}$ reserves will drive up prices $[5,6]$. With concerns over future rising $\mathrm{Li}$ costs $\left(\mathrm{Li}_{2} \mathrm{CO}_{3}\right.$ $\approx 3800 € /$ ton in 2010 vs. Na mineral 'trona' $\approx 120 € /$ ton), NIBs have re-emerged as candidates for medium and large-scale stationary energy storage $[4,5,7,8]$ due to sodium's high abundance $(\mathrm{Na}=$ $2.3 \%$ vs. $\mathrm{Li}=0.0017 \%$ of Earth's crust), low cost and encouraging redox potential of $E^{0}\left(\mathrm{Na} / \mathrm{Na}^{+}\right)=-2.71 \mathrm{~V}$ vs. SHE - only $0.3 \mathrm{~V}$ above that of $\mathrm{Li}$, and the possibility of using electrode/anode/current collector combinations.

This shift from Li- to Na-ion technologies has to be accompanied with a deeper understanding of the chemical reactions involving the multiple cell components. The application of a non-invasive analysis tool that can follow the reactions is therefore highly desired. In situ nuclear magnetic resonance (NMR) spectroscopy was recently shown to be a valuable tool for these real-time studies of battery materials under operating conditions [6,9-16]. Since the first in situ experiments approximately 15 years ago, two approaches regarding the NMR probe and/or the cell design have been established [11,17]: Toroid probeheads [18-20] and the use of commercial static NMR probes in which either Bellcore-type bag cells [21-27] or Swagelok-type plastic insets [28] were used. The toroid is both part of the electrochemical cell and NMR detector and was designed as a "battery imager" probe in its final set-up [18-20]. A drawback of this design is an inherently low signal to noise $(\mathrm{S} / \mathrm{N})$ and complicated analysis of the spectra due to non-linear radio frequency (RF) excitation/detection. Higher sensitivity and flexibility was achieved by placing the electrochemical cell inside the coil of a static NMR probe, connecting it to an external potentiostat (electrochemical cycler, EC) and acquiring the NMR spectra as a function of charge [11]. Depending on the battery components and its sensitivity to moisture and air, various designs exist for the bag cells, e.g. using $\mathrm{Cu}$ or Al meshes or foil as the current collector, polyester or Al bags as the container and contact heat sealers vs. lamination for the cell assembly [21-27]. The use of Swagelok-type cylindrical plastic insets instead of flat bag cells improves the pressure on the cell and its electrochemical performance but introduces a poor filling factor and respective issues with the signal intensity. Furthermore, the orientation of the battery with respect to the magnetic field is also not necessarily optimum.

In situ NMR shows high chemical specificity, allows the detection of dynamical processes, metastable and short-lived phases and is sensitive to both crystalline and amorphous species. Despite in situ NMR being such a fundamental technique, it comes with challenges. Significantly different shifts, changing sample conditions, signal broadening, and interferences of the NMR and EC circuit can impair the experiments:

- Shift ranges. An electrochemical cell is a multi-component device, normally comprising a solid anode and cathode as well as a liquid electrolyte. The different components cover large shift ranges that are determined by chemical shift, Knight shift, and anisotropic NMR 
interactions [29]. The electrolyte and solid-electrolyte-interphase (SEI) ${ }^{6,7} \mathrm{Li}$ signals normally appear in the diamagnetic range of -10 to $10 \mathrm{ppm}$; the range for ${ }^{23} \mathrm{Na}$ is only slightly larger. Many times, Li or Na metal strips are used as anodes with Knight shifted resonances at 242 and $1126 \mathrm{ppm}$, respectively, for a horizontal alignment of the metal strip to the magnetic field $[6,17]$. Furthermore, these shifts are orientation dependent due to bulk magnetic susceptibility (BMS) effects resulting in $272 \mathrm{ppm}$ (Li) and $1131 \mathrm{ppm}(\mathrm{Na})$ for a vertical orientation of the metal stripe to the magnetic field $[6,17,29]$. Finally, the active material of the cathode can range over thousands of ppm $[6,17,29]$. Hence, simultaneous detection can be challenging and often requires varying carrier frequencies during the NMR experiment.

- Changing sample conditions. The properties of the materials building up the cell can change during electrochemical cycling, e.g., non-metallic materials can become metallic or semiconducting, or a new microstructure may form that influences the magnetic susceptibility of the electrodes. The changes can affect the optimal NMR measurement conditions that have been set up for the pristine cell. Therefore, signal detectability and line shape measurement can be influenced and recalibration of the NMR circuit is needed.

- NMR signal broadening. In addition to the shift interactions (chemical/Knight shift) the signal line shape of the battery materials can be influenced by quadrupole coupling and paramagnetic broadening [29]. In particular, the hyperfine interaction with unpaired electrons in paramagnetic materials often gives rise to very broad resonances since many battery components are paramagnetic. Furthermore, BMS effects affect the signal shift and linewidth $[12,17,29]$. Sample shape, packing of the material (particles) and sample orientation with respect to the static magnetic field give rise to BMS effects.

- NMR-EC circuit interferences. The implementation of an electrochemical cell connected to an EC inside of a NMR coil can cause interferences between the alternating current of the NMR and direct current of the EC circuits. In worst case scenarios this influences both the electrochemical performance and NMR detectability.

In this matter, we developed and explored the use of a new Automatic Tuning Matching Cycler (ATMC) in situ NMR probe system. The ATMC in situ NMR approach addresses some of these difficulties allowing an "on-the-fly" adjustment of the NMR circuit during the measurement. Moreover, new sample holder and NMR-EC-connection designs benefit the real-time experiments, improving the compression on the battery, the filling factor, and shielding.

Automatic tuning/matching (T/M) is a routinely applied technique in solution-state NMR: motors attached to the $\mathrm{T} / \mathrm{M}$ rods below the probe are automatically, software-controlled adjusted to calibrate the resonance circuit after changing samples and/or switching nuclei. A similar approach using external motors has been reported by Hwang [30]; further automatic T/M capabilities due to variable capacitors controlled by direct current voltage have been developed for T/M multifrequency saddle coils in magnetic resonance imaging [31].

In this contribution, we first describe the ATMC probe, report on the pitfalls during set-up and data acquisition of an in situ NMR experiment and give practical considerations on how the ATMC in situ NMR approach is beneficial to overcome some of the challenges associated with this technique (Results and Discussion, Section 4.1 and Supporting Information). Furthermore, we discuss the application of the ATMC in situ NMR methodology on LiFePO and $\mathrm{Na}_{3} \mathrm{~V}_{2}\left(\mathrm{PO}_{4}\right)_{2} \mathrm{~F}_{3}$ cathodes as well as $\mathrm{Na}$ metal anodes (Results and Discussion, Sections 4.2 to 4.4.) after shortly introducing their application and challenges in battery research (Materials System Investigated, Section 2). The materials in question were chosen to focus on challenges in the NMR detectability of paramagnetic broadened cathodes, the formation of intermediate phases and the investigation of electrolyte decomposition during cycling of LIBs and NIBs. Experimental NMR strategies especially addressing the automatic recalibration capabilities of the ATMC system in frequency sweep and wideline NMR experiments are described. 


\section{Materials Systems Investigated}

\section{1. $\mathrm{LiFePO}_{4}$ as a Cathode in a LIB}

LFP nanoparticle electrodes have recently been shown to form nonequilibrium solid solution phases $\mathrm{Li}_{x} \mathrm{FePO}_{4}(0 \leq x \leq 1)$ during high rate cycling as a LIB $[32,33]$. These studies used in situ X-ray diffraction (XRD) to prove that metastable/intermediate $\mathrm{Li}_{x} \mathrm{FePO}_{4}$ phases are formed bypassing the thermodynamically stable nucleation and growth mechanism for (de)lithiation. The metastable/intermediate phases are likely to be the key for the high rate capabilities of LFP [32]. The formation of the metastable/intermediate phases in LFP can be monitored using two NMR active nuclei $-{ }^{7} \mathrm{Li}$ and ${ }^{31} \mathrm{P}$ - that will give information sensitive to the changes in the local structure on the processes of charging (delithiation) and discharge (lithiation) of LFP cathodes in a LIB. Hence, the application of in situ NMR to LFP is a promising method to gain insight into the changes of the Li and $P$ environments of the material during electrochemical cycling that potentially will complement synchrotron-based experiments.

\section{2. $\mathrm{Na}_{3} \mathrm{~V}_{2}\left(\mathrm{PO}_{4}\right)_{2} \mathrm{~F}_{3}$ as a Cathode in a NIB}

$\mathrm{Na}_{3} \mathrm{~V}_{2}\left(\mathrm{PO}_{4}\right)_{2} \mathrm{~F}_{3}$ is a potential cathode material for a NIB, with rapid Na motion being at least partially responsible for its high rate performance [34]. The long-range crystal structure and symmetry is highly dependent on Na-ion stoichiometry (content), dynamics and disorder and some of the details are still under debate (Supporting Information, Section SI-1.). $\mathrm{Na}_{3-\mathrm{x}} \mathrm{V}_{2}\left(\mathrm{PO}_{4}\right)_{2} \mathrm{~F}_{3}$ with $x=0$ was first published in the space group $P 4_{2} / m n m$, comprising $\mathrm{F}-\mathrm{V}\left(\mathrm{O}_{4}\right) \mathrm{FV}\left(\mathrm{O}_{4}\right)-\mathrm{F}$ dimers and $\mathrm{PO}_{4}$ tetrahedra with two crystallographic $\mathrm{Na}$ as well as $\mathrm{P}$ sites in the framework [35]. This structure was confirmed by recent $\mathrm{X}$-ray and neutron diffraction experiments as well as calculation and NMR studies (Supporting Information, Section SI-1.) [34,36,37]. Structural refinements for $\mathrm{Na}_{3-x} \mathrm{~V}_{2}\left(\mathrm{PO}_{4}\right)_{2} \mathrm{~F}_{3}$ with $x=$ 1 and 2 were performed in the space groups $14 / \mathrm{mmm}$ and $C m c 2_{1}$, respectively, both possessing only one P site (Supporting Information, Section SI-1.) [38].

Recent ex situ ${ }^{31} \mathrm{P}$ magic angle spinning (MAS) NMR investigations show a high sensitivity to local atomic ordering of the $\mathrm{Na}$ and $\mathrm{P}$ atoms and enabled a study of the mechanisms associated with the structural changes in in $\mathrm{Na}_{3-\mathrm{x}} \mathrm{V}_{2}\left(\mathrm{PO}_{4}\right)_{2} \mathrm{~F}_{3}$ during electrochemical cycling [34]. Two $\mathrm{P}$ sites ( $\mathrm{P} 1$ and $\mathrm{P} 2$ at 6096 and 4600 ppm, respectively), minor defects within the framework (P(def) at 3100, 2000, and $1200 \mathrm{pm}$ ), as well as highly oxidised impurities ( $\mathrm{P}(\mathrm{ox})$ at $0 \mathrm{ppm}$ ) are revealed for $x=0$ (Figure S4, Section SI-1.4.). Upon charge (desodiation), the P1 and P2 signal intensities decrease very quickly and vanish for $x=1$ (Figure S4). Moreover, two new P environments ( P1' $^{\prime}$ and $P 2^{\prime}$ at 3749 and 2605 ppm, respectively) were found for $\mathrm{Na}_{3-x} \mathrm{~V}_{2}\left(\mathrm{PO}_{4}\right)_{2} \mathrm{~F}_{3}$ with $1.4 \leq x \leq 2.0$ (Figure $\mathrm{S} 4$ ), in apparent contradiction with the space groups $14 / \mathrm{mmm}$ and $\mathrm{Cmc2}_{1}$ (Supporting Information, Section SI-1).

The use of ${ }^{31} \mathrm{P}$ in situ NMR is a promising method to further understand and investigate the relationship between the local atomic $P$ environments and the dynamics of both electrons and $\mathrm{Na}$ ions. The challenge is the detection of the respective ${ }^{31} \mathrm{P}$ NMR signals that are, based on ex situ studies, likely to range from 0 to $6100 \mathrm{ppm}$ [34]. The resulting ${ }^{31} \mathrm{P}$ NMR frequency span requires different NMR carrier frequencies, which is challenging for in situ studies.

\subsection{Na Metal Anodes}

The formation of high surface area microstructures with dendritic or mossy shapes during electrochemical cycling is known to cause short circuits, battery failure, and fire in many cases. In situ NMR is a valuable tool to monitor and quantify the formation of the metallic species formed $[6,9]$. Hereby, symmetrical $\mathrm{Li}-\mathrm{Li}$ or $\mathrm{Na}-\mathrm{Na}$ cells are used and continuous galvanostatic (constant current) plating is applied (Experimental Section). Hence, only a NMR signal of the electrolyte and its decomposition products (forming the SEI layer) in the diamagnetic shift region and a signal of the Li or Na metal strip at 242 and $1126 \mathrm{ppm}$ (horizontal orientation [6,17]) are present, respectively. So far, in situ NMR studies have generally focused on the metal signal since the microstructure formation gives rise to changes in shift and signal lineshape $[9,12,17]$. Although the 
electrolyte and SEI layer are thought to be key in dendrite formation $[6,9,15,39]$, the electrolyte peak has not been studied extensively to date with in situ experiments. The spin-lattice-relaxation times of the diamagnetic species in the electrolyte are different from that of the Li metal and previous NMR experiments have been optimised for the latter. Hence, a simultaneous detection of both signals during an in situ NMR experiment is a promising approach to gain further insights into the underlying chemistries.

\section{Experimental Section}

\subsection{Sample Preparation}

All electrochemical cells were assembled under argon atmosphere in a glove box $\left(\mathrm{O}_{2}, \mathrm{H}_{2} \mathrm{O}<0.1 \mathrm{ppm}\right)$ using flexible polyester plastic bags (VWR International) that were hermetically sealed with an impulse sealer in the final step $[6,17]$. All electrochemical reactions were conducted with the ECLab $^{\circledast}$ software version 10.40 on either a Bio-Logic VSP or SP-150 portable cycler.

\subsection{1. $\mathrm{LiFePO}_{4}$}

$\mathrm{LiFePO}_{4} / \mathrm{C}$ composites were synthesised as recently described [32] following a solid-state reaction developed by Kobayashi et al. [40]. $0.556 \mathrm{~g}$ lithium carbonate $\left(\mathrm{Li}_{2} \mathrm{CO}_{3}\right.$, Sigma-Aldrich, $\left.99.997 \%\right)$, $2.681 \mathrm{~g}$ iron(II) oxalate dihydrate $\left(\mathrm{Fe}(\mathrm{II}) \mathrm{C}_{2} \mathrm{O}_{4} \cdot \mathrm{H}_{2} \mathrm{O}\right.$, Sigma-Aldrich, 99\%), $1.714 \mathrm{~g}$ ammonium dihydrogen phosphate $\left(\mathrm{NH}_{4} \mathrm{H}_{2} \mathrm{PO}_{4}\right.$, Sigma-Aldrich, 99.999\%), and $0.261 \mathrm{~g}$ Ketjen black (EC-600JD AkzoNobel) were high energy ball-milled for $40 \mathrm{~min}$ to produce homogeneously mixed precursors. The precursors were then pressed into a pellet and sintered at $600^{\circ} \mathrm{C}$ for 6 hours under flowing argon gas. Self-supporting $\mathrm{LiFePO}_{4} / \mathrm{C}$ cathode films were produced by mixing the respective $\mathrm{LiFePO}_{4} / \mathrm{C}$ composite powder (120 mg) with polytetrafluoroethylene (PTFE) binder (Sigma-Aldrich), Super P carbon (Alfa Aesar), and Ketjen black carbon (EC-600JD AkzoNobel) in a mass ratio of 6:1:1.5:1.5 in a mortar. The mixture was rolled to a film of $1 \mathrm{~mm}$ thickness and cut to a $6 \times 9 \mathrm{~mm}^{2}$ rectangle with a total mass of $35 \mathrm{mg}$. The cathode film was assembled with Li foil $199.9 \%$, traces metals basis, Sigma-Aldrich) as the anode, glass fibre (Whatman) as the separator, and $1 \mathrm{M}$ lithium hexafluorophosphate solution in ethylene carbonate and dimethyl carbonate $\left(\mathrm{LiPF}_{6}\right.$ in $E C / D M C=50 / 50(v / v)$, battery grade, $1 M$ LiPF $_{6} E C / D M C$, Sigma Aldrich) as the liquid electrolyte. The cathode was connected with Al mesh (Dexmet Corporation, Wallingford, CT, 1.5Al 6-077F $\times 12^{\prime \prime}$ ), the anode with $\mathrm{Cu}$ mesh (Dexmet Corporation, Wallingford, CT, $1.5 \mathrm{Cu} 6-077 \mathrm{~F} \times 12^{\prime \prime}$ ). The cell was charged/discharged at a constant current of $0.360 \mathrm{~mA}$, which corresponds to $\mathrm{C} / 10$ rate [32].

\subsection{2. $\mathrm{Na}_{3} \mathrm{~V}_{2}\left(\mathrm{PO}_{4}\right)_{2} \mathrm{~F}_{3}$}

A mixture 1:2:2 (molar ratio) of vanadium(V)oxide $\left(\mathrm{V}_{2} \mathrm{O}_{5}\right.$, Sigma-Aldrich, 99.99\%), phosphoric acid $\left(\mathrm{H}_{3} \mathrm{PO}_{4}\right.$, Sigma-Aldrich, 85\%) and citric acid (Sigma-Aldrich, $\left.\geq 99.5 \%\right)$ was dissolved in deionised water, continuously stirred at $80^{\circ} \mathrm{C}$ for 12 hours and then dried at $120^{\circ} \mathrm{C}$ for 4 hours to form a uniform gel [34]. The gel was ball-milled for 6 hours, pressed into pellets, and heated at $350^{\circ} \mathrm{C}$ for 6 hours and at $700^{\circ} \mathrm{C}$ for another 6 hours in an argon atmosphere to obtain $\mathrm{VPO}_{4}$. Afterwards, $\mathrm{NaF}$ (SigmaAldrich) and $\mathrm{VPO}_{4}$ were mixed in a stoichiometric ratio of $3: 2$, pressed into pellets, fired at $700^{\circ} \mathrm{C}$ under argon flow for 6 hours, and finally cooled down to ambient temperature. The carbon content in the resulting $\mathrm{Na}_{3} \mathrm{~V}_{2}\left(\mathrm{PO}_{4}\right)_{2} \mathrm{~F}_{3} / \mathrm{C}$ composite was determined to be $6 \mathrm{wt}$. $\%$ by elemental analysis [41]. The positive electrode consisted of 75 wt.- $\% \mathrm{Na}_{3} \mathrm{~V}_{2}\left(\mathrm{PO}_{4}\right)_{2} \mathrm{~F}_{3} / \mathrm{C}$ composite, 15 wt.-\% Super $\mathrm{P}$ carbon (Alfa Aesar), and 10 wt.-\% PTFE binder (Sigma-Aldrich). Sodium metal (Sigma-Aldrich, 99.9\%, cuts from cubes) supported on a current collector was used as the negative electrode. The two electrodes were separated by a piece of glass fibre (Whatman) sheet immersed in $1 \mathrm{M} \mathrm{NaClO}_{4}$ (Sigma-Aldrich, $\geq 98.0 \%$ ) in propylene carbonate (PC) solution (Sigma-Aldrich, anhydrous, 99.7\%). Al mesh (Dexmet) was used as a current collector on the $\mathrm{Na}_{3} \mathrm{~V}_{2}\left(\mathrm{PO}_{4}\right)_{2} \mathrm{~F}_{3}$ side and $\mathrm{Cu}$ mesh (Dexmet) on the Na metal side. The cell was charged/discharged by applying a current of $3.2 \mathrm{~mA} \cdot \mathrm{g}^{-1}$ resulting in a $\mathrm{C} / 40$ rate; the applied voltage window was 2.5 to $4.5 \mathrm{~V}$. 


\subsubsection{Na Metal Anodes}

$1 \mathrm{M} \mathrm{Na-bis(trifluoromethylsulfonyl)imide} \mathrm{(NaTFSI)} \mathrm{in} \mathrm{PC} \mathrm{electrolyte} \mathrm{was} \mathrm{prepared} \mathrm{as} \mathrm{recently}$ described [6]. Symmetrical $\mathrm{Na}$ metal bag cells were assembled with $\mathrm{Cu}$ mesh (Dexmet) current collectors and freshly prepared $\mathrm{Na}$ metal strips (Sigma-Aldrich, 99.9\%, cut from cubes) with dimensions of $10 \times 5 \times 0.5 \mathrm{~mm}^{3}$. Continuous galvanostatic (constant current) plating with $+500 \mu \mathrm{A}$ was applied to the $\mathrm{Na}-\mathrm{Na}$ cell during the in situ NMR experiment.

\subsection{Solid-State NMR Spectroscopy}

All NMR experiments were performed at ambient temperature with the ATMC in situ NMR probe system attached to Bruker Avance I or Avance III HD consoles at magnetic field strengths of $7.05 \mathrm{~T}$. The respective resonance frequencies for ${ }^{7} \mathrm{Li},{ }^{23} \mathrm{Na}$, and ${ }^{31} \mathrm{P}$ are $116.59,79.36$, and $121.44 \mathrm{MHz}$, respectively. The experiments were performed using solenoid coils of $8 \mathrm{~mm}$ diameter and $6-8$ turns made of Ag-coated $\mathrm{Cu}$ wire. The chemical shifts are referenced to $9.7 \mathrm{~mol} \cdot \mathrm{kg}^{-1} \mathrm{LiCl}$ and $0.1 \mathrm{~mol} \cdot \mathrm{L}^{-1}$ $\mathrm{NaCl}$ solutions in $\mathrm{D}_{2} \mathrm{O}$ and $85 \% \mathrm{H}_{3} \mathrm{PO}_{4}$, respectively [42-44]. Bruker Topspin 2.1 and 3.2 as well as Matlab was used for raw data processing and analysis. Single- or echo-pulse sequences have been used for the NMR data collection (Figure S5). The sequences have been enhanced by a preamble to enable the synchronisation of the auto T/M algorithm - in which a low power $(0.01 \mathrm{~W})$ continuous wave (CW) pulse was applied - prior the actual NMR experiment (Figure S6). The temperature was adjusted to $20^{\circ} \mathrm{C}$ by a $900 \mathrm{Lph}$ nitrogen gas flow and very little heating using the internal Bruker VTU. The gas flow is furthermore beneficial to prevent the electrochemical cell from local overheating during the in situ NMR experiment. In addition, a constant nitrogen gas stream of 100 mbar was applied on the capacitors to prevent local overheating during high rate pulsing. Bag cells were set up in the ATMC in situ NMR probe system and cycled as described in the text.

\subsection{1. ${ }^{7} \mathrm{Li}$ and ${ }^{31} \mathrm{P} \mathrm{NMR}$ on $\mathrm{LiFePO}_{4}$}

${ }^{7} \mathrm{Li}$ and ${ }^{31} \mathrm{P}$ wideline NMR experiments were performed with an echo pulse sequence applying high power $(200 \mathrm{~W}) 1.5-3.0 \mu \mathrm{s}\left({ }^{7} \mathrm{Li}\right)$ and $1.0-2.0 \mu \mathrm{s}\left({ }^{31} \mathrm{P}\right)$ pulses at a recycle delay of $0.05 \mathrm{~s}$. An echo pulse sequence with low power $(0.1 \mathrm{~W})$, selective $50-100 \mu$ s pulses was applied during the frequency sweep experiments (Figure S7). Frequency ranges of 1.0 and $0.5 \mathrm{MHz}$ for ${ }^{7} \mathrm{Li}$ and ${ }^{31} \mathrm{P}$ were measured in $10 \mathrm{kHz}$ steps, respectively.

\subsection{2. ${ }^{31} \mathrm{PNMR}$ on $\mathrm{Na}_{3} \mathrm{~V}_{2}\left(\mathrm{PO}_{4}\right)_{2} \mathrm{~F}_{3}$}

${ }^{31} \mathrm{P}$ wideline in situ NMR experiments were performed with an auto $\mathrm{T} / \mathrm{M}$ in situ echo pulse sequence at carrier frequencies of $121.5,122.0$, and $122.2 \mathrm{MHz}$ (with respective offsets of 100,4000 , and 5900 $\mathrm{ppm}$ ) applying high power $(220 \mathrm{~W}) 1.0 \mu$ s pulses at a recycle delay of $0.05 \mathrm{~s}$. A low power $(0.01 \mathrm{~W})$ $\mathrm{CW}$ pulse was applied during the automatic T/M sequences. An ex situ ${ }^{31} \mathrm{P}$ MAS NMR experiment (4.70 T, $60 \mathrm{kHz}$ MAS frequency, Bruker DR MAS $1.3 \mathrm{~mm}$ probehead with $1.3 \mathrm{~mm} \mathrm{ZrO}_{2}$ rotor) was exclusively performed on pristine $\mathrm{Na}_{3} \mathrm{~V}_{2}\left(\mathrm{PO}_{4}\right)_{2} \mathrm{~F}_{3}$ powder using a onepulse sequence with hard pulses of 1.0 us pulse length and a recycle delay of $0.05 \mathrm{~s}$ (Supporting Information, Figure S4b).

\subsection{3. ${ }^{23} \mathrm{Na} \mathrm{NMR}$ on $\mathrm{Na}-\mathrm{Na}$ Cells}

${ }^{23} \mathrm{Na}$ wideline NMR experiments at carrier frequencies of 79.5 and $79.4 \mathrm{MHz}$ for the $\mathrm{Na}$ metal and electrolyte signal, respectively, were performed using a onepulse sequence with high power pulses of $7.7 \mu \mathrm{s}$ (metal peak) and $6.0 \mu \mathrm{s}$ (electrolyte peak) length and a recycle delay of $1.0 \mathrm{~s}$.

\section{Results and Discussion}

\subsection{The ATMC In Situ NMR System}

The design and development of the ATMC in situ NMR system was done in close collaboration with NMR Service GmbH (Erfurt, Germany). A basic model (probehead, T/M controller box, and software) is now commercially available [45]; however, other experimental considerations (e.g. filters, materials, cell type, etc.), which are described in this paper for the systems studied here, may be important to obtain high quality data. 
Our ATMC in situ NMR system comprises a one channel static widebore solid-state NMR probehead with interchangeable coils enabling a tuning range of $74 \mathrm{MHz}$ to $125 \mathrm{MHz}$ at $7.05 \mathrm{~T}$ (Figure 1A). The system is usable in a temperature range of $-150^{\circ} \mathrm{C}$ to $200^{\circ} \mathrm{C}$ and is compatible with Bruker Avance I to III HD as well as Tecmag consoles. The low $Q$ design is suitable for non-selective (hard) $\pi / 2$ pulses $\leq 2 \mu$ s at up to $500 \mathrm{~W}$ radiofrequency (RF) power. The main features to differentiate our system from other static NMR probeheads are its capability for an "on-the-fly" recalibration of the resonance circuit as well as a straightforward and highly-shielded connection of electrochemical cells inside the RF coil (Figure 1).
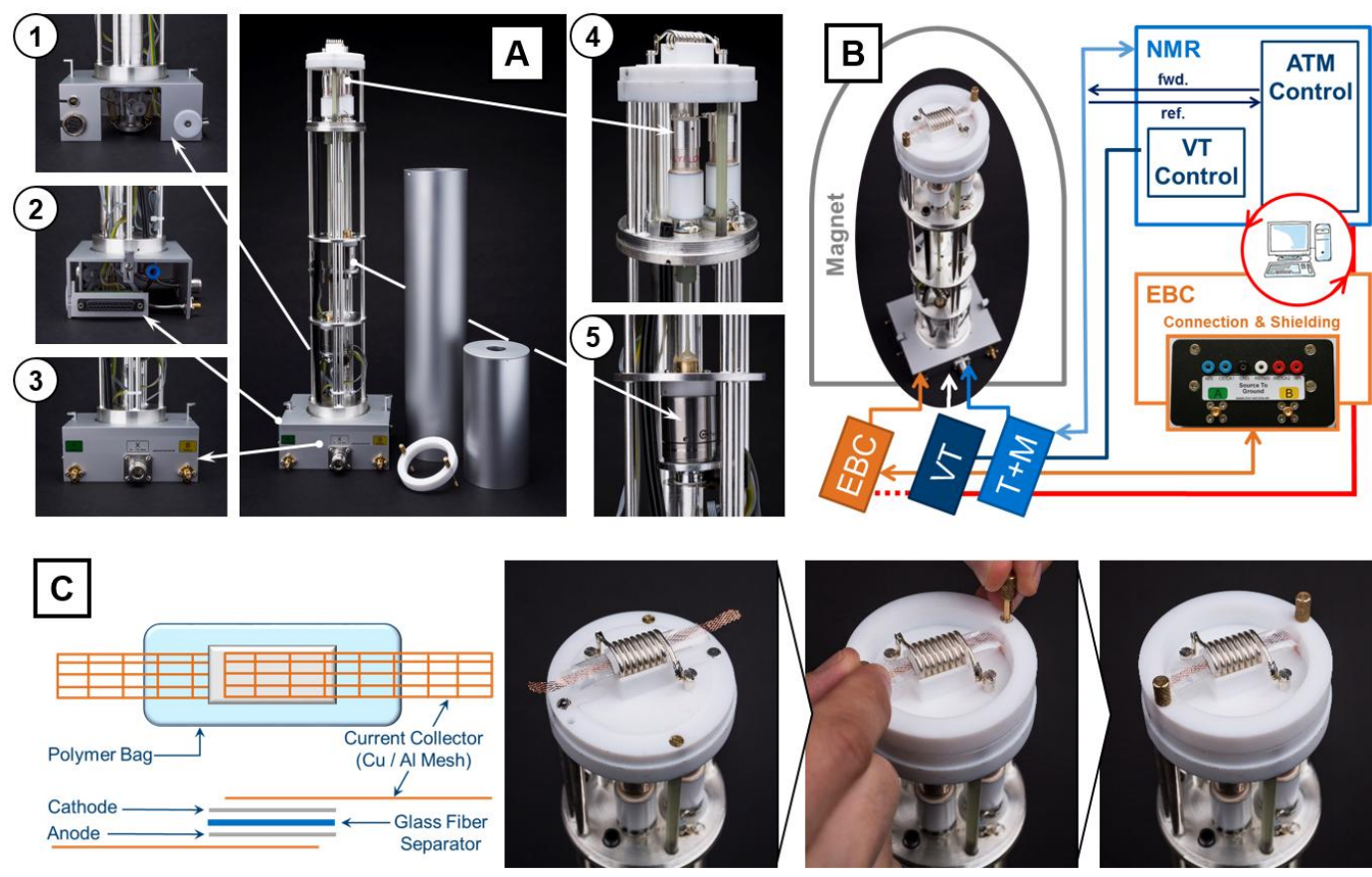

Figure 1. (A) The Automatic Tuning Matching Cycler (ATMC) in situ NMR probe system, comprising the probehead bottom connections to the variable temperature unit (A1), to the eATM controller (A2), as well as the RF and EC connectors (A3). Furthermore, the Polyflon T/M capacitors (A4) and one of the piezoelectric engines for automatic T/M are depicted (A5). (B) Scheme of the interplay and synchronisation of the ATMC NMR probe system with the EC. (C) Schematic drawing of a plastic bag cell design and its set-up for an in situ NMR experiment.

\subsubsection{Automatic Tuning/Matching Capability}

The RF circuit comes with two resistance-free adjustable Polyflon capacitors for $\mathrm{T} / \mathrm{M}$ as well as an additional $5 \mathrm{pF}$ static matching capacitor that can be attached to the RF circuit if needed (Figure $1 \mathrm{~A}$, Figure S8). The adjustable capacitors are attached to piezoelectric engines inside the probe. The encoders for these engines are connected to an external automatic T/M (eATM) unit (Figure 1B). Before the NMR experiment, a low power CW pulse is given on the RF circuit at the desired carrier frequency and bypassed from the preamplifier into the eATM via a bi-directional coupler. The software-controlled eATM determines the standing wave ratio (SWR) and return loss (RL) using the incoming forwarded and reflected power of the CW pulse at the current setting of the RF circuit with respect to the carrier frequency. Automatic T/M ("on-the-fly" recalibration of the RF circuit) is then enabled through eATM synchronised changes of the capacitors via the piezoelectric engines and a respective RL/SWR recalculation. This loop is repeated until a RL minimum is reached, which corresponds to a perfect match of the RF circuit's impendence and the desired carrier frequency. The synchronisation of the eATM and the NMR console is controlled via TTL inputs (Figure 1B), and defined in the preamble of the applied pulse sequence (Figure S5, Figure S6) [46]. 
The automatic T/M capability of the ATMC in situ NMR system is beneficial for both frequency sweep NMR experiments using a stepwise selective excitation of large spectral widths as well as an automatic recalibration of the RF circuit during an in situ NMR experiment with constant or varying carrier frequencies. A perfectly calibrated NMR circuit is a key for the detection of broadened NMR signals such as those from paramagnetic samples or quadrupolar nuclei since poor $\mathrm{T} / \mathrm{M}$ results in a loss of RF power that can cause limited signal excitation, line shape distortions and poor signal intensity.

\subsubsection{Electrochemistry Connection (Cell Set-Up and Shielding)}

An electrochemical cell inside the RF coil can influence the otherwise perfect shielding of the RF circuit. This can result in noise being picked up as well as significant interferences of the EC-NMR circuits (Figure S9). Hence, as important as the good T/M mentioned above, effective shielding of both circuits is crucial to achieve NMR detectability and good S/N ratios. Therefore, the ATMC in situ NMR system comes with a new design to connect to electrochemical cell inside the NMR coil as well as highly shielded wire connections in- and outside the NMR probehead to connect the EC and the NMR circuit (Figure 1C). The electrochemical cell is placed inside the coil with the current collector (meshes or foil) extending outside the coil. A Teflon ring surrounding the coil presses the current collectors of the cell to the leads at the top of the probehead. The overall set-up and connection of a cell is therefore both highly reproducible and time efficient.

The presence of the electrochemical cell connected to the EC acts as an antenna introducing noise that is detected by the NMR circuit. The insertion of RF low pass filters at the electrochemistry connection ports of the probehead bottom reduces this noise, as detected in the wobble curves (Figure 1A, Figure S9). A low pass filter allows the direct currents from the EC to pass, while removing unwanted alternating current noise, thus filters with a low frequency cut-off are preferable. Details and practical considerations on setting up an ATMC in situ NMR experiment are given in the Supporting Information (Section SI-2).

\section{2. ${ }^{7} \mathrm{Li}$ and ${ }^{31} \mathrm{PNMR}$ on $\mathrm{LiFePO}_{4}$ as a Cathode in a LIB}

${ }^{7}$ Li NMR measurements on both the pristine LFP powder and an electrochemical cell at two different stages of charge reveal the major challenges: the slightly asymmetric NMR signal of the cathode is $700 \mathrm{kHz}$ broad and - in the cell - overlaps completely with the metal and electrolyte signals (Figure 2a). A decrease of the LFP signal intensity is detected for the half charged cell and in agreement with the delithiation of the crystal structure (Figure 2a).

In this case, the automatic T/M capability of the ATMC probe approach enables a straightforward detection of the huge spectral width by automated frequency sweep (also known as frequency step [47]) experiments over $1 \mathrm{MHz}$ in $10 \mathrm{kHz}$ steps applying selective pulses (Figure S7, Experimental Section). This technique is well known for significantly broadened line shapes of quadrupolar nuclei $[46,48-51]$ and other kinds of so-called ultra-wideline NMR spectra covering frequency ranges of approx. $250 \mathrm{kHz}$ to tens of $\mathrm{MHz}[47,52]$. A second and complementary approach involves the use of larger step widths and shorter pulses (giving rise to broader excitation widths). These spin-echo mapping [53-58], referred to by some authors as variable offset cumulative spectrum (VOCS) [5962], experiments could also be used to detect these signals, and could be conducted with the ATMC system.

A very good $\mathrm{S} / \mathrm{N}$ for the selectively excited spectra at each sweep carrier frequency is achieved within two minutes and the respective T/M times for automatic recalibration during the applied 10 $\mathrm{kHz}$ steps is three minutes. Hence, each sweep experiment for a $1 \mathrm{MHz}$ frequency range takes approx. eight hours. A reduction of the spectral width to the at least required $700 \mathrm{kHz}$ still results in an overall time of six hours for $10 \mathrm{kHz}$ steps and approx. three hours for $20 \mathrm{kHz}$ steps, which still would be suitable. Nevertheless, the overall experimental times for the sweep experiments are timewise not suitable for in situ NMR experiments, particularly under conditions of fast cycling. Therefore, the pristine cell signal was measured with wideline NMR excitation to assess the 
detectability of especially the broad LFP signal line shape. A good $\mathrm{S} / \mathrm{N}$ is already achieved within 10 minutes measurement time. A comparison of sweep vs. wideline NMR reveals a satisfying detection of the desired LFP signal feature throughout the wideline experiment (Figure 2b, Experimental Section, Figure S7). Hence, the application of wideline excitation during in situ NMR is certainly suited for LFP.

The ATMC in situ ${ }^{7} \mathrm{Li}$ NMR measurement shows a continuous decrease of the broad LFP cathode signal during discharge and its recovery during charge (Figure 2c). Still, the overlap of the Li metal and electrolyte with the LFP signal complicates the monitoring of changes in the LFP signal line shape during charge and discharge.
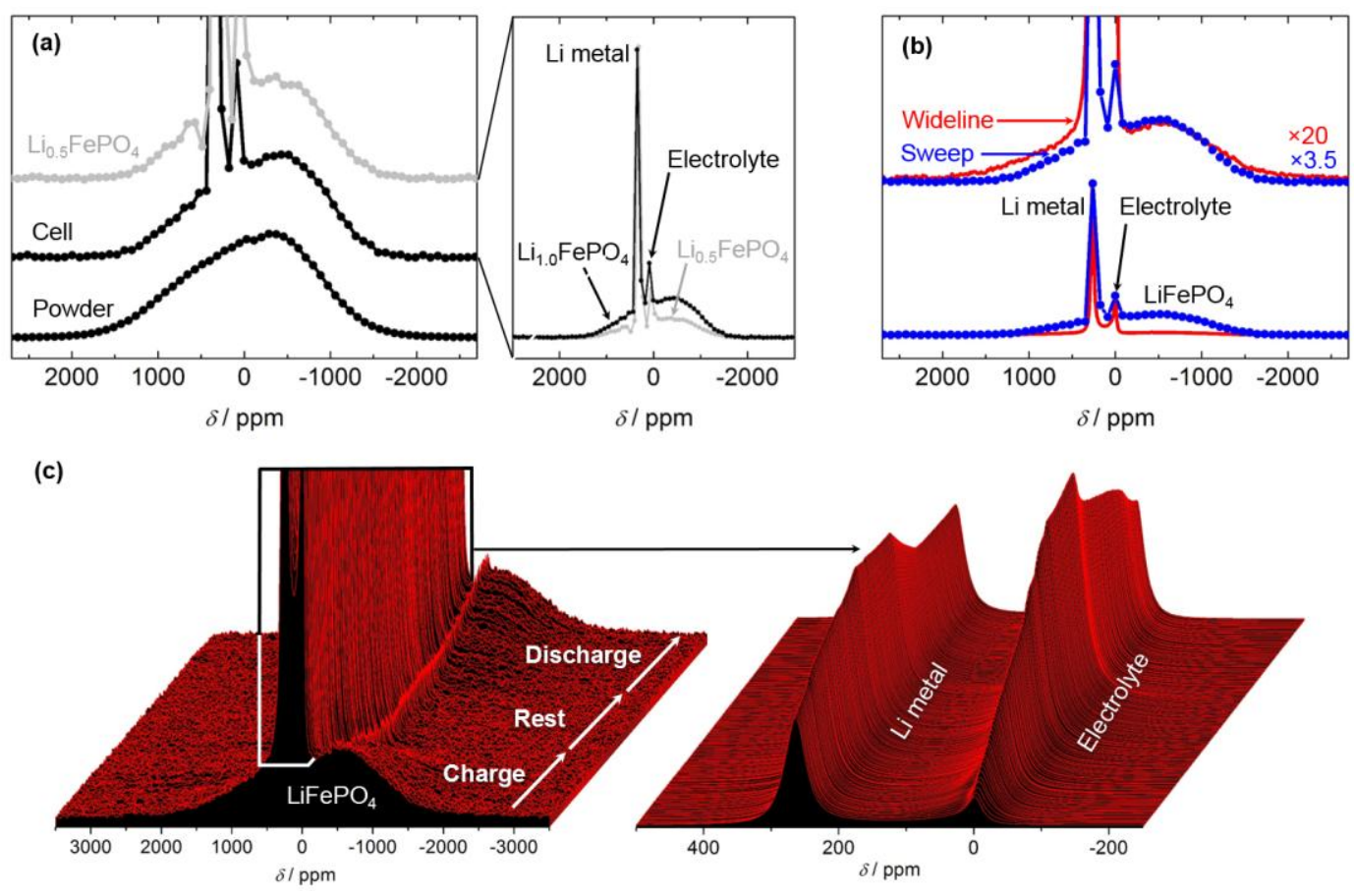

Figure 2. (a) ${ }^{7} \mathrm{Li}$ frequency sweep NMR spectra of pristine $\mathrm{LiFePO}_{4}$ powder (black) as well as a pristine (black) and half charged (grey, $\mathrm{Li}_{0.5} \mathrm{FePO}_{4}$ ) LFP bag cell. The zoom shows the bag cell spectra normalised against the maximum intensity of the Li metal peak. (b) ${ }^{7}$ Li NMR spectrum of the pristine LFP bag cell using wideline (red) and frequency sweep (blue) NMR. The bottom shows the spectra normalised against the maximum intensity of the Li metal peak. The top shows the intensities of the wideline and frequency sweep spectra scaled up times 20 and 3.5, respectively, to highlight the line shape of the broad LFP signal feature. (c) In situ ${ }^{7}$ Li wideline NMR spectra during C/10 charge, rest, and C/10 discharge of a LFP bag cell (left). The -250 to $500 \mathrm{ppm}$ zoom exclusively shows the electrolyte and Li metal signals (right). Signal contributions originating from the respective cell components (electrolyte, metal, and active material) are labelled in the figures.

${ }^{31} \mathrm{P}$ NMR experiments solve the problem of overlapping signals observed with ${ }^{7} \mathrm{Li}$, since the cathode and electrolyte signal are well separated (Figure 3a). Furthermore, wideline vs. frequency sweep ${ }^{31} \mathrm{P}$ NMR experiments provide satisfactory detection of the line shape during broadband excitation. ${ }^{31} \mathrm{P}$ in situ NMR on a LFP bag cell used an automatic re-calibration of the carrier frequency during the electrochemical cycling and shows the potential of this second source of NMR information: the intensity of the two well separated ${ }^{31} \mathrm{P}$ NMR signals corresponding to LFP and FP, respectively, continuously vary as the battery undergoes charge and discharge (Figure $3 b$ ). 

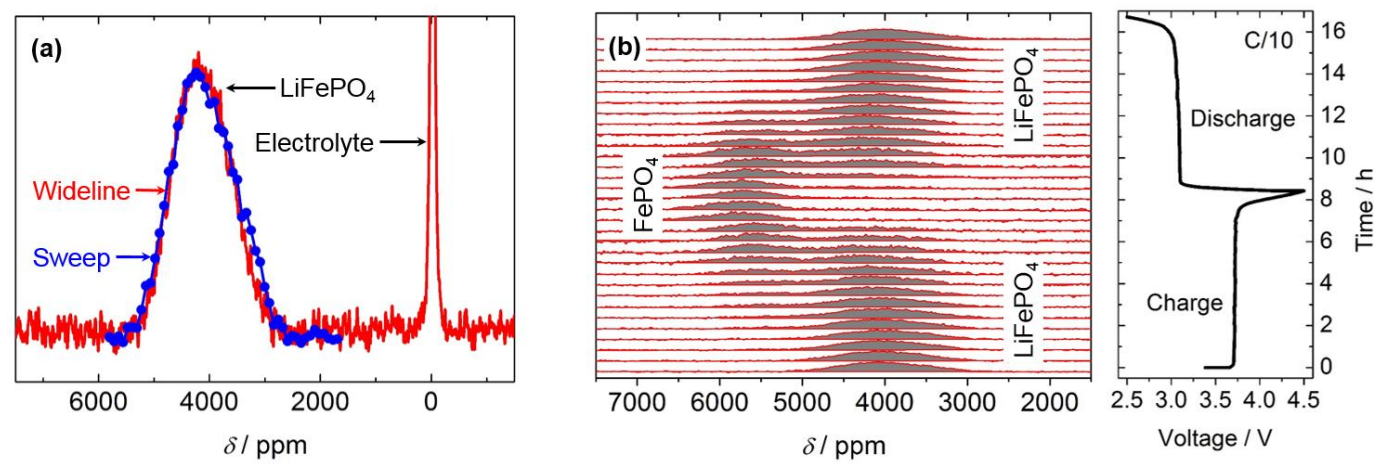

Figure 3. (a) ${ }^{31} \mathrm{P}$ wideline (red) vs. frequency sweep (blue) NMR spectra of a pristine LFP/Li bag cell. The LiPF 6 electrolyte signal occurs at $0 \mathrm{ppm}$. (b) In situ ${ }^{31} \mathrm{P}$ spectra during $\mathrm{C} / 10$ charge and discharge (right figure) indicating the signal ranges of $\mathrm{LiFePO}_{4}$ and $\mathrm{FePO}_{4}$.

\section{3. $\quad{ }^{31} \mathrm{P}$ In Situ NMR on $\mathrm{Na}_{3} \mathrm{~V}_{2}\left(\mathrm{PO}_{4}\right)_{2} \mathrm{~F}_{3}$ as a Cathode in a NIB}

Applying the ATMC in situ NMR approach we derived an experimental set-up that automatically recalibrated the carrier frequency to offsets of 4000 and $5900 \mathrm{ppm}$ and acquired the respective data during a slow charge/discharge of the cell (Figure 4). The ${ }^{31} \mathrm{P}$ in situ NMR data in Figure 4 shows the 2000 to 8000 ppm range focusing on the major P signals and not the ones due to defects P(def) or oxidised impurities $P(\mathrm{ox})$ (Materials Systems Investigated, Section 2.2.). Nevertheless, we carefully checked the pristine $\mathrm{Na}_{3} \mathrm{~V}_{2}\left(\mathrm{PO}_{4}\right)_{2} \mathrm{~F}_{3}$ material by ex situ ${ }^{31} \mathrm{P}$ MAS and show in situ ${ }^{31} \mathrm{P}$ data acquired between -1000 to $8000 \mathrm{ppm}$ in the Supporting Information (Figure S4b, Figure S10). The low intensity $\mathrm{P}\left(\right.$ def) signal is no longer detectable in static ${ }^{31} \mathrm{P}$ in situ $\mathrm{NMR}$, presumably due to the large line broadening due to large $\mathrm{P}$-electron dipolar interactions and their low concentrations (Figure S4, Figure S10). Furthermore, the $\mathrm{P}(\mathrm{ox})$ signal is very weak in intensity and only detectable when the carrier frequency is set to $100 \mathrm{ppm}$ (Figure S10). No significant changes of the $\mathrm{P}(\mathrm{ox})$ intensity occur during charging the cell; the $\mathrm{P}(\mathrm{ox})$ signal remains barely detectable and is generally of minor interest regarding changes of the local atomic environments in the $\mathrm{Na}_{3-\mathrm{x}} \mathrm{V}_{2}\left(\mathrm{PO}_{4}\right)_{2} \mathrm{~F}_{3}$ cathode during desodiation (Figure S10).

${ }^{31} \mathrm{P}$ in situ NMR measurements on $\mathrm{Na}_{3-x} \mathrm{~V}_{2}\left(\mathrm{PO}_{4}\right)_{2} \mathrm{~F}_{3}$ with $x=0$ reveal the two $\mathrm{P} 1$ and $\mathrm{P} 2$ environments expected for the crystal structure (Figure 4, Materials Systems Investigated, Supporting Information, Section SI-1). The shifts of 6900 and $5400 \mathrm{ppm}$ for P1 and P2 are slightly larger than reported for MAS experiments (Figure S4a) [34]. This is due to the elevated temperature of the sample inside the MAS rotor under fast spinning, which decreases the effect of the paramagnetic $\mathrm{V}^{3+}$ centre on the $\mathrm{P}$ atoms. Upon charge (desodiation) of $\mathrm{Na}_{3-x} \mathrm{~V}_{2}\left(\mathrm{PO}_{4}\right)_{2} \mathrm{~F}_{3}(x=0)$ the $\mathrm{P} 1$ and $\mathrm{P} 2$ signal intensities vanish due to changes in the $\mathrm{V}$ oxidation states and the Na-ion movement, which both influence the local $\mathrm{P}$ environments (Figure 4), in agreement with ex situ MAS studies (Figure S4a) [34].

Interestingly, the ${ }^{31} \mathrm{P}$ in situ NMR experiments reveal a signal at $4500 \mathrm{ppm}$, denoted as $\mathrm{P}$-ii, for $\mathrm{Na}_{3-x} \mathrm{~V}_{2}\left(\mathrm{PO}_{4}\right)_{2} \mathrm{~F}_{3}$ with $x=1$, while our previous ex situ NMR study did not show a signal for this composition (Figure 4, Figure S4a). We assign the P-ii signal as the average of the P1 and P2 environments since the P-ii intensity is almost equal to the sum of P1+P2. The P-ii shift is smaller than the ones for $\mathrm{P} 1$ and $\mathrm{P} 2$ at $x=0$ but noticeably larger than the ones for $\mathrm{P}^{\prime}$ and $\mathrm{P} 2^{\prime}$ at $x=2\left(\mathrm{P} 1^{\prime}\right.$ at 3749 and $P 2^{\prime}$ at 2605 ppm, Figure S4a). Hence, the P-ii shift is in agreement with a $\mathrm{V}^{3+}$ to $\mathrm{V}^{3.5+}$ change of oxidation state for the cathode since typical ${ }^{31} \mathrm{P}$ shifts for $\mathrm{P}$ in the proximity of $\mathrm{V}^{3+}, \mathrm{V}^{4+}$, and diamagnetic $V^{5+}$ are reported to be $>4000,1500-4000$, and close to 0 ppm, respectively [58]. The P-ii signal indicates only one $\mathrm{P}$ environment being present at $x=1$, which supports the crystal structure description in space group $14 / \mathrm{mmm}$ with one P site (Supporting Information, Section SI-1) [38]. The lack of any ${ }^{31} \mathrm{P}$ signal for $\mathrm{Na}_{3-\mathrm{x}} \mathrm{V}_{2}\left(\mathrm{PO}_{4}\right)_{2} \mathrm{~F}_{3}$ with $x=1$ in ex situ MAS experiments (Figure S4a) is presumably due to an increased sample temperature, leading to faster mobility of the $\mathrm{Na}$-ions and 
electrons in the structure. Presumably, a significant peak broadening, different spin-spin relaxation times and a loss of the signal detectability results. A further desodiation of $\mathrm{Na}_{3-x} \mathrm{~V}_{2}\left(\mathrm{PO}_{4}\right)_{2} \mathrm{~F}_{3}$ to $x=2$ causes the P-ii signal to disappear while a new signal at 3000 ppm occurs, denoted as P-iii (Figure 4). Its shift indicates a further increase of the $\mathrm{V}$ oxidation state from $\mathrm{V}^{3.5+}$ to $\mathrm{V}^{4+}$ and is furthermore the average of the $\mathrm{P}^{\prime}$ ' and $\mathrm{P} 2$ ' signal shifts seen by ex situ NMR for this composition (Figure S4a). This (dis)appearance of the different ${ }^{31} \mathrm{P}$ in situ signals is reversible upon discharge and reveals the potential of the in situ NMR study to gain insights into structural changes beyond the scale of ex situ techniques. The observation of only one $\mathrm{P}$ site at $\mathrm{Na}_{3-x} \mathrm{~V}_{2}\left(\mathrm{PO}_{4}\right)_{2} \mathrm{~F}_{3}$ with $x=1$ and 2 is in agreement with our structural refinements and choice of space group (Figures S2 and S3) as well as earlier in situ diffraction measurements (Supporting Information, Section SI-1) [38]. We suggest that the observation of two different $\mathrm{P}$ environments in the ex situ NMR measurements is related to the $\mathrm{Na}$ ordering that may occur for samples that have been allowed to relax before data collection. Samples measured in situ, either by NMR or by diffraction, are likely to contain more disordered Naenvironments; this may also be associated with increased Na-mobility. Differences in the concentrations of defects in the different samples may also play a role in controlling Na disorder.
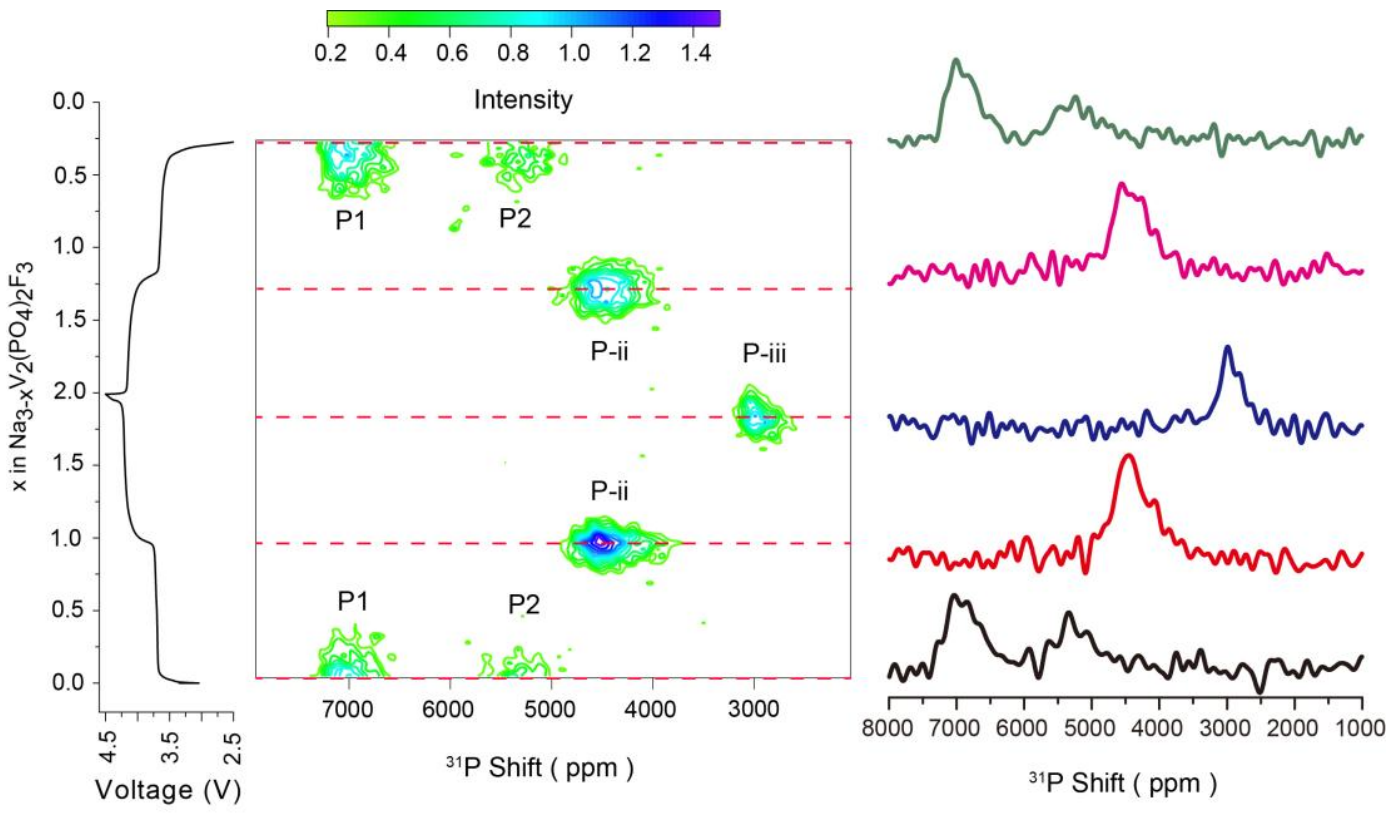

Figure 4. Charge/discharge curve (left), ${ }^{31} \mathrm{P}$ in situ NMR spectra of a $\mathrm{Na}_{3} \mathrm{~V}_{2}\left(\mathrm{PO}_{4}\right)_{2} \mathrm{~F}_{3} / \mathrm{Na}$ cell (middle), and slices of the $2 \mathrm{D}$ NMR contour plot at the horizontally marked (red dashed lines) states of charge at the right. Different NMR carrier frequencies with 4000 and 5900 ppm offset were applied and automatically adjusted during the in situ NMR experiment. Different phosphorous signals are labelled as $\mathrm{P} 1, \mathrm{P} 2, \mathrm{P}$-ii, and $\mathrm{P}$-iii indicating varying chemical environments due to the crystal structure of the pristine (P1, P2) and desodiated (P-ii, P-iii) material, respectively [34].

\section{4. $\quad{ }^{23} \mathrm{Na}$ In Situ NMR on Na Metal Anodes}

A simultaneous measurement of both the Na metal and electrolyte signal comes with a compromise regarding signal excitation due to large spectral offsets and spectral distortions due to susceptibility and skin-depth effects. For Na cells, the frequency span between the ${ }^{23} \mathrm{Na} N \mathrm{NMR}$ signals for the electrolyte (-8 ppm) and metal (1126 ppm) is $90 \mathrm{kHz}$ (Figure 5a). This offset is much larger than for Li cells. Thus, on-resonance conditions cannot be fulfilled for both signals as long as a fixed carrier frequency is used during the experiment. This can cause distortions of the line shape, which can result in inaccurate quantification of the signal intensities. Furthermore, the $\mathrm{Na}$ metal and electrolyte show different spin-lattice-relaxation times of $9.3 \mathrm{~ms}$ (metal) and $1.6 \mathrm{~ms}$ (electrolyte) as well as nutation behaviours with optimal $\pi / 2$ pulse lengths of $7.7 \mu \mathrm{s}$ (metal) and $6.0 \mu \mathrm{s}$ (electrolyte). 
The longer pulse length for the metal is due to skin depth effects [6]. Additionally, the formation of metallic microstructures influences the susceptibility of the cell, which can affect the optimal experimental conditions for the in situ NMR measurement as set up on the pristine cell.

Hence, the respective NMR parameters need to be first optimised on the pristine cell in separate experiments with the carrier frequency set to the corresponding signal maximum of the electrolyte and metal peak, respectively (Figure 5a, Experimental Section). These two measurements are then repeated for the duration of the electrochemical experiment with an automatic re-calibration of the carrier frequency back- and forward to the respective frequency. Thus the on-resonance conditions allow a quantification of both the metal and electrolyte signal during the in situ NMR experiment.
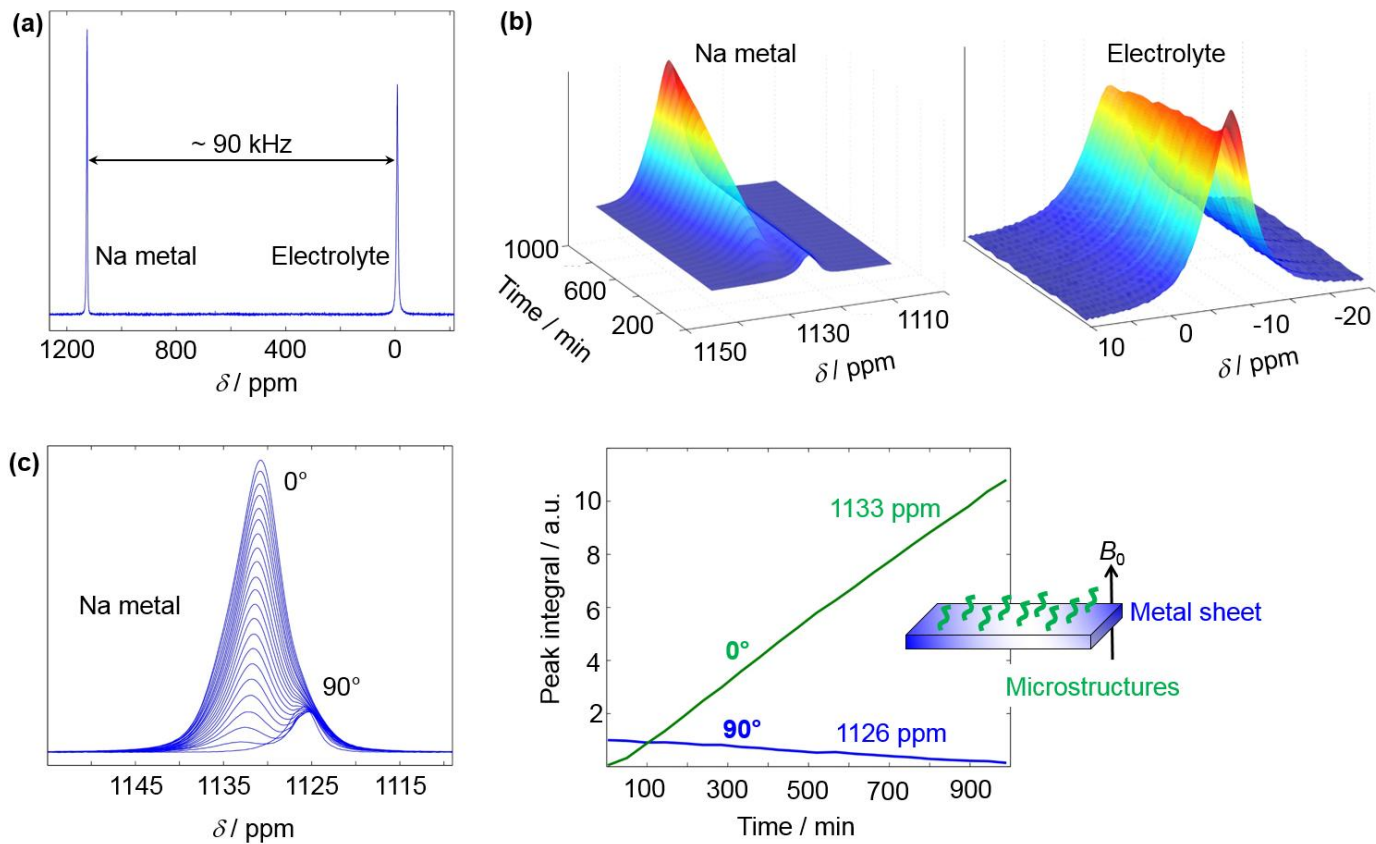

Figure 5. (a) ${ }^{23} \mathrm{Na}$ NMR spectra of a pristine symmetrical $\mathrm{Na}-\mathrm{Na}$ cell made of $\mathrm{Na}$ metal and NaTFSI electrolyte considering NMR carrier frequencies of $1130 \mathrm{ppm}$ (metal) and $0 \mathrm{ppm}$ (electrolyte), respectively. (b) ${ }^{23} \mathrm{Na}$ in situ NMR spectra of the $\mathrm{Na}$ metal (left) and $\mathrm{Na}$ electrolyte (right) peaks during galvanostatic cycling with $+500 \mu \mathrm{A}$ for 12 hours. (c) Peak integral vs. time of the deconvoluted Na metal signal regarding the metal sheet (blue) and microstructure (green) signal contributions.

During galvanostatic plating the intensity of the ${ }^{23} \mathrm{Na}$ metal peak at $1126 \mathrm{ppm}$ decreases and the signal is slightly shifted to higher frequencies and broadened (Figure $5 b$ ). Furthermore, a second signal at $1133 \mathrm{ppm}$ appears, constantly increasing and dominating the overall lineshape of the $\mathrm{Na}$ metal signals after approximately 1.5 hours of galvanostatic plating. The second signal is due to $\mathrm{Na}$ microstructures that are formed on the bulk surface, growing perpendicular to the metal strip and therefore parallel with the magnetic field (Figure $5 \mathrm{c}$ ). Hence, this signal is shifted to $1133 \mathrm{ppm}$ due to anisotropic BMS effects $[6,9,17]$ (Figure 5c).

The experimental resolution during ATMC ${ }^{23} \mathrm{Na}$ in situ NMR is significantly improved and also enables a detection of the electrolyte signal during the electrochemical experiment (Figure 5b). The analysis of the ${ }^{23} \mathrm{Na}$ electrolyte NMR signal shows an approximate $5 \%$ decrease of its intensity during the experiment. Such a reduction in the amount of electrolyte $\mathrm{Na}^{+}$signal, hence concentration of ions in solution, is likely to be related to the formation of insoluble Na species that result from electrolyte decomposition during SEl formation. This in situ quantification of Na-ion consumption is to our knowledge the first time reported and only made possible via ATMC in situ NMR. 


\section{Conclusions}

We have developed and applied a new ATMC in situ NMR probe system that addresses many of the technical challenges for real-time investigations of LIBs and NIBs throughout "on-the-fly" recalibration of resonance circuit and a new connection set-up for electrochemical cells in the NMR probe. We reported on the pitfalls during set-up and in situ NMR data acquisition and discussed practical considerations for setting up such kind of experiments and for the use of ATMC in situ NMR.

The first applications on the cathode material LFP show the benefit of automated frequency sweep NMR experiments to detect strongly paramagnetic broadened ${ }^{7} \mathrm{Li}$ and ${ }^{31} \mathrm{P}$ NMR signals. Automated recalibration of the carrier frequency enables the detection of broad ${ }^{31} \mathrm{P} N M R$ signals in $\mathrm{Na}_{3} \mathrm{~V}_{2}\left(\mathrm{PO}_{4}\right)_{2} \mathrm{~F}_{3}$ cathode material as well interleaved, on-resonant $\mathrm{NMR}$ measurements of $\mathrm{Na}$ electrolyte and $\mathrm{Na}$ metal signals in symmetrical $\mathrm{Na}-\mathrm{Na}$ cells. In the $\mathrm{Na}_{3} \mathrm{~V}_{2}\left(\mathrm{PO}_{4}\right)_{2} \mathrm{~F}_{3}$ system, averaged $P$ environments are detected, the results highlighting the difference in samples studied ex and in situ.

Ongoing research attempts focus on the implementation of pulse sequences containing adiabatic pulses similar to those used in wideline quadrupolar NMR [47] and broadband paramagnetic NMR [63]. The current challenge of to build a cell that is capable of high-rate cycling of cathodes with no capacity fade will be overcome by the implementation of a new electrochemical cell design in combination with computer synchronised electrochemistry and NMR experiments. Alternative coil materials like pure silver or Manganin could be of benefit regarding low or high $Q$ values of the resonance circuit. Furthermore, the implementation of a goniometer attached to the ATMC in situ NMR probe system is envisioned and will be likely to use automated sample orientation changes for time-efficient investigations of the BMS effects on the NMR signal shift and line shape $[12,17]$. By applying all these approaches, the ATMC methodology should allow in situ NMR spectroscopy to be applied to an ever increasing range of battery materials and systems.

\section{Acknowledgements}

The collaboration with Marco Braun (NMR Service GmbH, Erfurt, DE) on NMR probehead design and manufacturing is gratefully acknowledged. We acknowledge Baris Key, Rangeet Bhattacharrya and Revolution NMR LLC (Fort Collins, CO, USA) for the development of the first generation in situ NMR probes. We thank David Bennett (Bruker Biospin, Rheinstetten, DE), Andrew J. Pell (Cambridge, UK), and Peter Grice (Cambridge, UK) for fruitful discussions and Nathan Pitt (Cambridge, UK) for technical support. C.P.G. and Z.L. acknowledge Prof. Yong Yang (Xiamen, China) and his group for ongoing collaborations on $\mathrm{Na}_{3} \mathrm{~V}_{2}\left(\mathrm{PO}_{4}\right)_{2} \mathrm{~F}_{3}$. O.P. and P.M.B. gratefully acknowledge financial support through a Marie Skłodowska-Curie Individual Fellowship (H2020-MSCA-IF-2014-EF, \#655444) and FP7 Marie Curie International Incoming Fellowship, respectively. Research was supported in part by the NorthEast Center for Chemical Energy Storage (NECCES), an Energy Frontier Research Center funded by the U.S. Department of Energy, Office of Science, Basic Energy Sciences under Award \# DE-SC0012583 (LFP materials, H.L., and N.M.T.), and by the Assistant Secretary for Energy Efficiency and Renewable Energy, Office of Vehicle Technologies of the U.S. Department of Energy, under contract no. DE-AC02-05CH11231, under the Batteries for Advanced Transportation Technologies Program subcontract 7057154 (Na metal).

\section{Appendix A. Supplementary Material}

Supplementary data associated with this article can be found in the online version at DOI needs to be added. 


\section{References}

[1] J.B. Goodenough, Basic Research Needs for Electrical Energy Storage, Off. Basic Energy Sci. Dep. Energy. (2007) 186.

[2] J. Tarascon, M. Armand, Issues and challenges facing rechargeable lithium batteries, Nature. 414 (2001) 359-367.

[3] M. Armand, J. Tarascon, Building better batteries, Nature. 451 (2008) 652-657.

[4] B.L. Ellis, L.F. Nazar, Sodium and sodium-ion energy storage batteries, Curr. Opin. Solid State Mater. Sci. 16 (2012) 168-177.

[5] M. Slater, D. Kim, E. Lee, C. Johnson, Sodium-Ion Batteries, Adv. Funct. Mater. 23 (2013) 947-958.

[6] P.M. Bayley, N.M. Trease, C.P. Grey, Insights into Electrochemical Sodium Metal Deposition as probed with In Situ ${ }^{23} \mathrm{Na}$ NMR, J. Am. Chem. Soc. in press (2016). doi:10.1021/jacs.5b1242.

[7] B. Dunn, H. Kamath, J.-M. Tarascon, Electrical Energy Storage for the Grid: A Battery of Choices, Science. 334 (2011) 928-935.

[8] R.J. Clément, P.G. Bruce, C.P. Grey, Manganese-Based P2-Type TransitionMetal Oxides as Sodium-lon Battery Cathode Materials, J. Electrochem. Soc. 162 (2015) A2589-A2604.

[9] R. Bhattacharyya, B. Key, H. Chen, A.S. Best, A.F. Hollenkamp, C.P. Grey, In situ NMR observation of the formation of metallic lithium microstructures in lithium batteries., Nat. Mater. 9 (2010) 504-510.

[10] B. Key, R. Bhattacharyya, M. Morcrette, V. Seznéc, J.-M. Tarascon, C. Grey, Real-Time NMR Investigations of Structural Changes in Silicon Electrodes for Lithium-Ion Batteries, J. Am. Chem. Soc. 131 (2009) 9239-9249.

[11] F. Blanc, M. Leskes, C.P. Grey, In situ solid-state NMR spectroscopy of electrochemical cells: Batteries, supercapacitors, and fuel cells, Acc. Chem. Res. 46 (2013) 1952-1963.

[12] L. Zhou, M. Leskes, A.J. Ilott, N.M. Trease, C.P. Grey, Paramagnetic electrodes and bulk magnetic susceptibility effects in the in situ NMR studies of batteries: Application to $\mathrm{Li}_{1.08} \mathrm{Mn}_{1.92} \mathrm{O}_{4}$ spinels, J. Magn. Reson. 234 (2013) 4457.

[13] P. Harks, F.M. Mulder, P.H.L. Notten, In situ methods for Li-ion battery research: A review of recent developments, J. Power Sources. 288 (2015) 92-105.

[14] O. Pecher, H. Liu, C.P. Grey, Next level real-time studies of $\mathrm{LiFePO}_{4}$ electrodes by ${ }^{7} \mathrm{Li}$ in situ NMR, Z. anorg. allg. Chem. 640 (2014) 2339.

[15] H.J. Chang, N.M. Trease, A.J. Ilott, D. Zeng, L.-S. Du, A. Jerschow, et al., Investigating Li Microstructure Formation on Li Anodes for Lithium Batteries by In Situ ${ }^{6}$ Li/ ${ }^{7}$ Li NMR and SEM, J. Phys. Chem. C. 119 (2015) 16443-16451.

[16] D. Itkis, J. Velasco-Velez, A. Knop-Gericke, A. Vyalikh, M. Avdeev, L. Yashina, Probing Operating Electrochemical Interfaces by Photons and Neutrons, Chem. Electro. Chem. (2015) 1-16.

[17] N.M. Trease, L. Zhou, H.J. Chang, B.Y. Zhu, C.P. Grey, In situ NMR of lithium ion batteries: Bulk susceptibility effects and practical considerations, Solid State Nucl. Magn. Reson. 42 (2012) 62-70.

[18] R.E. Gerald, R.J. Klingler, G. Sandi, C.S. Johnson, L.G. Scanlon, J.W. Rathke, ${ }^{7}$ Li NMR study of intercalated lithium in curved carbon lattices, J. Power Sources. 89 (2000) 237-243.

[19] R.E. Gerald, J. Sanchez, C.S. Johnson, R.J. Klingler, J.W. Rathke, In situ nuclear magnetic resonance investigations of lithium ions in carbon electrode materials using a novel detector, J. Phys Condes. Matter. 13 (2001) 8269-8285.

[20] J.W. Rathke, R.J. Klingler, R.E. Gerald, K.W. Kramarz, K. Woelk, Toroids in NMR spectroscopy, Prog. Nucl. Magn. Reson. Spectrosc. 30 (1997) 209-253.

[21] J.M. Tarascon, A.S. Gozdz, C. Schmutz, F. Shokoohi, P.C. Warren, Performance of Bellcore's plastic rechargeable Liion batteries, Solid State Ionics. 86-8 (1996) 49-54.

[22] M. Letellier, F. Chevallier, C. Clinard, E. Frackowiak, J.-N. Rouzaud, F. Béguin, et al., The first in situ ${ }^{7}$ Li nuclear magnetic resonance study of lithium insertion in hard-carbon anode materials for Li-ion batteries, J. Chem. Phys. 118 (2003) 6038.

[23] F. Chevallier, M. Letellier, M. Morcrette, J.-M. Tarascon, E. Frackowiak, J.-N. Rouzaud, et al., In Situ ${ }^{7}$ Li-Nuclear Magnetic Resonance Observation of Reversible Lithium Insertion into Disordered Carbons, Electrochem. SolidState Lett. 6 (2003) A225-A228. 
[24] M. Letellier, F. Chevallier, F. Béguin, E. Frackowiak, J.N. Rouzaud, The first in situ ${ }^{7}$ Li NMR study of the reversible lithium insertion mechanism in disorganised carbons, J. Phys. Chem. Solids. 65 (2004) 245-251.

[25] M. Letellier, F. Chevallier, F. Béguin, In situ ${ }^{7}$ Li NMR during lithium electrochemical insertion into graphite and a carbon/carbon composite, J. Phys. Chem. Solids. 67 (2006) 1228-1232.

[26] M. Letellier, F. Chevallier, M. Morcrette, In situ ${ }^{7}$ Li nuclear magnetic resonance observation of the electrochemical intercalation of lithium in graphite; $1^{\text {st }}$ cycle, Carbon N. Y. 45 (2007) 1025-1034.

[27] J. Arai, Y. Okada, T. Sugiyama, M. Izuka, K. Gotoh, K. Takeda, In Situ Solid State ${ }^{7}$ Li NMR Observations of Lithium Metal Deposition during Overcharge in Lithium Ion Batteries, J. Electrochem. Soc. 162 (2015) A952-A958.

[28] F. Poli, J.S. Kshetrimayum, L. Monconduit, M. Letellier, New cell design for in-situ NMR studies of lithium-ion batteries, Electrochem. Commun. 13 (2011) 1293-1295.

[29] C.P. Grey, N. Dupré, NMR Studies of Cathode Materials for Lithium-Ion Rechargeable Batteries, Chem. Rev. 104 (2004) 4493-4512.

[30] F. Hwang, D.I. Hoult, Automatic probe tuning and matching, Magn. Reson. Med. 39 (1998) 214-222.

[31] R.P. de Alejo, C. Garrido, P. Villa, I. Rodriguez, J.J. Vaquero, J. Ruiz-Cabello, et al., Automatic tuning and matching of a small multifrequency saddle coil at 4.7 T., Magn. Reson. Med. 51 (2004) 869-73.

[32] H. Liu, F.C. Strobridge, O.J. Borkiewicz, K.M. Wiaderek, K.W. Chapman, P.J. Chupas, et al., Capturing metastable structures during high-rate cycling of $\mathrm{LiFePO}_{4}$ nanoparticle electrodes, Science. 344 (2014) 1252817.

[33] X. Zhang, M. Hulzen, D. Singh, A. Brownrigg, J. Wright, N. Dijk, et al., Rate-Induced Solubility and Suppression of the First-Order Phase Transition in Olivine LiFePO

[34] Z. Liu, Y.-Y. Hu, M.T. Dunstan, H. Huo, X. Hao, H. Zou, et al., Local Structure and Dynamics in the Na Ion Battery Positive Electrode Material $\mathrm{Na}_{3} \mathrm{~V}_{2}\left(\mathrm{PO}_{4}\right)_{2} \mathrm{~F}_{3}$, Chem. Mater. 26 (2014) 2513-2521.

[35] J.-M. Le Meins, M.-P. Crosnier-Lopez, A. Hemon-Ribaud, G. Courbion, Phase Transitions in the $\mathrm{Na}_{3} \mathrm{M}_{2}\left(\mathrm{PO}_{4}\right)_{2} \mathrm{~F}_{3}$ Family $\left(M=\mathrm{Al}^{3+}, \mathrm{V}^{3+}, \mathrm{Cr}^{3+}, \mathrm{Fe}^{3+}, \mathrm{Ga}^{3+}\right)$ : Synthesis, Thermal, Structural, and Magnetic Studies, J. Solid State Chem. 148 (1999) 260-277.

[36] R.A. Shakoor, D.-H. Seo, H. Kim, Y.-U. Park, J. Kim, S.-W. Kim, et al., A combined first principles and experimental study on $\mathrm{Na}_{3} \mathrm{~V}_{2}\left(\mathrm{PO}_{4}\right)_{2} \mathrm{~F}_{3}$ for rechargeable Na batteries, J. Mater. Chem. 22 (2012) 20535.

[37] Z. Liu, O. Pecher, C.P. Grey, Local atomic ordering in $\mathrm{Na}_{3} \mathrm{~V}_{2}\left(\mathrm{PO}_{4}\right)_{2} \mathrm{~F}_{3}$ as a cathode material for Na-ion batteries revisited by diffraction and ${ }^{23} \mathrm{Na} /{ }^{31} \mathrm{P}$ in situ NMR investigations, In preparation (2015).

[38] M. Bianchini, F. Fauth, N. Brisset, F. Weill, E. Suard, C. Masquelier, et al., Comprehensive Investigation of the $\mathrm{Na}_{3} \mathrm{~V}_{2}\left(\mathrm{PO}_{4}\right)_{2} \mathrm{~F}_{3}-\mathrm{NaV}_{2}\left(\mathrm{PO}_{4}\right)_{2} \mathrm{~F}_{3}$ System by Operando High Resolution Synchrotron X-ray Diffraction, Chem. Mater. 27 (2015) 3009-3020.

[39] S. Chandrashekar, N.M. Trease, H.J. Chang, L.-S. Du, C.P. Grey, A. Jerschow, ${ }^{7}$ Li MRI of Li batteries reveals location of microstructural lithium, Nat. Mater. 11 (2012) 311-315.

[40] G. Kobayashi, S. Nishimura, M.-S. Park, R. Kanno, M. Yashima, T. Ida, et al., Isolation of Solid Solution Phases in Size-Controlled $\mathrm{Li}_{x} \mathrm{FePO}_{4}$ at Room Temperature, Adv. Funct. Mater. 19 (2009) 395-403.

[41] X. Hao, Z. Liu, Z. Gong, W. Wen, S. Tan, Y. Yang, In situ XRD and solid state NMR characterization of $\mathrm{Na}_{3} \mathrm{~V}_{2}\left(\mathrm{PO}_{4}\right)_{2} \mathrm{~F}_{3}$ as cathode material for lithium-ion batteries, Sci. Sin. Chim. 42 (2011) 38-46.

[42] R.K. Harris, E.D. Becker, NMR Nomenclature: Nuclear Spin Properties and Conventions for Chemical Shifts-IUPAC Recommendations, J. Magn. Reson. 156 (2002) 323-326.

[43] R.K. Harris, E.D. Becker, S.M. Cabral de Menezes, R. Goodfellow, P. Granger, NMR nomenclature: nuclear spin properties and conventions for chemical shifts. IUPAC Recommendations 2001. International Union of Pure and Applied Chemistry. Physical Chemistry Division. Commission on Molecular Structure and Spectroscopy, Magn. Reson. Chem. 40 (2002) 489-505.

[44] R.K. Harris, E.D. Becker, S.M. De Cabral Menezes, P. Granger, R.E. Hoffman, K.W. Zilm, Further Conventions for NMR shielding and chemical shifts (IUPAC recommendations 2008), Magn. Reson. Chem. 46 (2008) 582-598.

[45] http://www.nmr-service.de/nmr-mas-static.html, NMR Service GmbH, Erfurt (Germany), 2016.

[46] O. Pecher, NMR Spectroscopy on Intermetallic Phases in the Systems $A E-\mathrm{Al}-\mathrm{Ga}$ with $A E=\mathrm{Ca}, \mathrm{Sr}$, and $\mathrm{Ba}$ Experimental and Theoretical Investigations of Chemical Bonding, RWTH Aachen University, 2013. 
[47] R.W. Schurko, Ultra-Wideline Solid-State NMR Spectroscopy, Acc. Chem. Res. 46 (2013) 1985-1995.

[48] M. Smith, Recent advances in experimental solid state NMR methodology for half-integer spin quadrupolar nuclei, Prog. Nucl. Magn. Reson. Spectrosc. 34 (1999) 159-201.

[49] D. Bräunling, O. Pecher, D.M. Trots, A. Senyshyn, D.A. Zherebtsov, F. Haarmann, et al., Synthesis, Crystal Structure and Lithium Motion of $\mathrm{Li}_{8} \mathrm{SeN}_{2}$ and $\mathrm{Li}_{8} \mathrm{TeN}_{2}$, Z. anorg. allg. Chem. 636 (2010) 936-946.

[50] O. Pecher, B. Mausolf, K. Lamberts, D. Oligschläger, C. Niewieszol (née Merkens), U. Englert, et al., The Solid Solution $\mathrm{Sr}_{1-\mathrm{x}} \mathrm{Ba}_{\mathrm{x}} \mathrm{Ga}_{2}$ : Substitutional Disorder and Chemical Bonding Visited by NMR Spectroscopy and Quantum Mechanical Calculations, Chem. Eur. J. 21 (2015) 13971-13982.

[51] F. Haarmann, Quadrupolar NMR of Intermetallic Compounds, in: R.K. Harris, R.E. Wasylishen (Eds.), eMagRes, John Wiley \& Sons, Ltd, Chichester, 2011.

[52] R.W. Schurko, Acquisition of Wideline Solid-State NMR Spectra of Quadrupolar Nuclei, in: R.K. Harris, R.E. Wasylishen (Eds.), eMagRes, John Wiley \& Sons, Ltd, Chichester, UK, 2011.

[53] G. Mali, A. Ristić, V. Kaucic, ${ }^{31} \mathrm{P}$ NMR as a tool for studying incorporation of $\mathrm{Ni}, \mathrm{Co}, \mathrm{Fe}$, and $\mathrm{Mn}$ into aluminophosphate zeotypes., J. Phys. Chem. B. 109 (2005) 10711-6.

[54] M.T. Sananes, A. Tuel, Magnetic properties of vanadium phosphorus oxide catalysts studied by Spin Echo Mapping ${ }^{31}$ P NMR, J. Chem. Soc. Chem. Commun. (1995) 1323.

[55] L. Canesson, A. Tuel, The first observation of "NMR-invisible phosphorus" in cobalt-substituted aluminophosphate molecular sieves, Chem. Commun. (1997) 241-242.

[56] Tong, Y. Tong, Y., Nuclear Spin-Echo Fourier-Transform Mapping Spectroscopy for Broad NMR Lines in Solids, J. Magn. Reson. Ser. A. 119 (1996) 22-28.

[57] M.T. Sananes, A. Tuel, G.J. Hutchings, J.C. Volta, Characterization of Different Precursors and Activated Vanadium Phosphate Catalysis by ${ }^{31}$ P NMR Spin Echo Mapping, J. Catal. 148 (1994) 395-398.

[58] M.T. Sananes, A. Tuel, Study by ${ }^{31}$ P NMR spin echo mapping of vanadium phosphorus oxide catalysts, Solid State Nucl. Magn. Reson. 6 (1996) 157-166.

[59] D. Massiot, I. Farnan, N. Gautier, D. Trumeau, A. Trokiner, J.P. Coutures, ${ }^{71}$ Ga and ${ }^{69}$ Ga nuclear magnetic resonance study of $\beta-\mathrm{Ga}_{2} \mathrm{O}_{3}$ : resolution of four- and six-fold coordinated Ga sites in static conditions, Solid State Nucl. Magn. Reson. 4 (1995) 241-248.

[60] J. Kim, D. Middlemiss, N. Chernova, Y. Zhu, C. Masquelier, C. Grey, Linking Local Environments and Hyperfine Shifts: A Combined Experimental and Theoretical ${ }^{31} \mathrm{P}$ and ${ }^{7}$ Li Solid-State NMR Study of Paramagnetic Fe(III) Phosphates, J. Am. Chem. Soc. 132 (2010) 16825-16840.

[61] R.W. Schurko, S. Wi, L. Frydman, Dynamic Effects on the Powder Line Shapes of Half-Integer Quadrupolar Nuclei: A Solid-State NMR Study of $\mathrm{XO}_{4}{ }^{-}$Groups, J. Phys. Chem. A. 106 (2002) 51-62.

[62] J.T. Ash, P.J. Grandinetti, Solid-state NMR characterization of ${ }^{69} \mathrm{Ga}$ and ${ }^{71} \mathrm{Ga}$ in crystalline solids., Magn. Reson. Chem. 44 (2006) 823-31.

[63] A.J. Pell, G. Pintacuda, Broadband solid-state MAS NMR of paramagnetic systems, Prog. Nucl. Magn. Reson. Spectrosc. 84 (2015) 33-72. 